\title{
On effect of superplasticizers and mineral additives on shrinkage of hardened cement paste and concrete
}

\author{
Grigory Nesvetaev ${ }^{1}$, Yulia Koryanova ${ }^{1, *}$, and Tatiana Zhilnikova $^{1}$ \\ ${ }^{1}$ DSTU, Department technology of construction production, 344000 Rostov-on-Don, sq. Gagarina,1, \\ Russia
}

\begin{abstract}
A model describing the variation in autogenous shrinkage and drying shrinkage of portland cement concrete, depending on the volume of aggregates and the shrinkage of hardened cement paste, is presented. The equation to calculate shrinkage of concrete as a function of the volume of aggregates and shrinkage of a hardened cement paste was proposed. Formulas are proposed that describe the change in the shrinkage of hardened cement paste as a function of water/cement. The results of studies of the effect of superplasticizers and mineral additives on the autogenous shrinkage and the drying shrinkage of hardened cement paste are presented. Concretes made with superplasticizer and mineral additive may have the potential lower the value of drying shrinkage. The shrinkage value can be lowered from $30 \%$ till $70 \%$. Concretes containing superplasticizers and mineral additives can potentially have the autogenous shrinkage reduced to $75 \%$, or increased to $180 \%$.
\end{abstract}

\section{Introduction}

Research on shrinkage of concrete with superplasticizers (SP) and mineral additives (MA) are relevant, especially in connection with the using of high-strength (HSC) and selfcompacting concretes (SCC) [1-3]. According to [4, 5], the role of the autogenous shrinkage can be very significant in the microcracking of cement stone and concrete. According to the data of [6], SCC shrinkage at the age of 28 days was from 0.26 to 0.32 . In $[7,8]$ there is an increase in shrinkage of SCC from $30 \%$ to $33 \%$, and in [10] - up to $12 \%$. In [9], a decrease in SCC shrinkage was obtained when fly ash was used. In [12] an increase of SCC shrinkage was not found in comparison with NC. SCC shrinkage problems, including the autogenous shrinkage, are discussed in $[1-4,11,13]$. The possibility of SCC shrinkage growth is noted in connection with the growth of volume of hardened cement paste. According to [14], SCC shrinkage can be reduced to two times when special additives are added to the concrete mixture. Thus, comparing the drying

\footnotetext{
*Corresponding author: Koryanova.yi@mail.ru
} 
shrinkage and the autogenous shrinkage of SCC with NC due to conflicting information requires further research.

\section{Methodology}

According to EN 1992-1-1, the total shrinkage of concrete consists of the drying shrinkage and the autogenous shrinkage

$$
\varepsilon_{\mathrm{CS}}=\varepsilon_{\mathrm{cd}}+\varepsilon_{\mathrm{ca}}
$$

and is determined as a function of the class of concrete and the relative humidity of the air.

It is well known that the drying shrinkage depends linearly on the $\mathrm{W} / \mathrm{C}$ of hardened cement paste, its chemical and mineralogical composition and fineness of grinding of cement, the volume of hardened cement paste in the concrete, the properties of aggregates, the effect of SP and MA and, in general, for real concrete, can be represented in the form [15]:

$$
\varepsilon_{S H, C}=f(C A) \cdot k_{S H, S P} \cdot\left(1-V_{A}\right)^{X} \cdot\left(2 \frac{W}{C}+0,18\right) \cdot \varepsilon_{S H, S P}=k_{S H, S P} \cdot k \cdot \varepsilon_{S H, S P}
$$

or

$$
\varepsilon_{S H, C}=k \cdot \varepsilon_{S H, S P}
$$

In Table 1 presents some data on the relationship between the drying shrinkage of hardened cement paste and concrete [15].

Table 1. The values of the coefficient $\mathrm{k}$ in eq. (3)

\begin{tabular}{|c|c|c|}
\hline № & Author & $\mathrm{k}$ \\
\hline 1 & Stolnikov V.V. & 0,1 \\
\hline 2 & Lermith R. & $1+\beta \mathrm{V}_{\mathrm{A}} / \mathrm{V}_{\mathrm{CS}}$, where $\beta=1,5-3,1$ \\
\hline 3 & Bazhenov Yu.M. & $1+\beta \mathrm{V}_{\mathrm{A}} / \mathrm{V}_{\mathrm{CS}}$, where $\beta=2,4-3,1$ \\
\hline 4 & Lewis R. & $\exp \left(-2 \mathrm{~V}_{\mathrm{A}}\right)$ \\
\hline 5 & Slavcheva G.S. & $\left(1-\mathrm{V}_{\mathrm{A}}\right)^{\alpha}$ \\
\hline 6 & Picket G. & $\left(1-\mathrm{V}_{\mathrm{A}}\right)^{\alpha}, \alpha=1,2-1,7$ \\
\hline 7 & Sheikin A.E. & $\left(\mathrm{V}_{\mathrm{CS}}\right)^{\alpha}, \alpha=1.4-1.8$ \\
\hline 8 & Shcherbakov E.N. & $0,15-0,13-$ hard concrete mixes; \\
\hline & & $0,2-0,23-$ mobile concrete mixes; \\
9 & Nesvetaev G.V. & $0,2-0,33-$ SCC \\
& &
\end{tabular}

SP and MA can influence on the drying shrinkage of hardened cement paste. In Table 2 shows the data on the ratio of shrinkage of hardened cement paste with SP in comparison

\begin{tabular}{|c|c|c|c|c|c|c|c|c|c|c|}
\hline \multirow{2}{*}{ SP } & \multicolumn{9}{|c|}{ Cement factories } & \multirow{2}{*}{ Range } \\
\hline & 1 & 2 & 3 & 4 & 5 & 6 & 7 & 8 & 9 & \\
\hline 1 & $\begin{array}{c}1,09 \\
- \\
1,62\end{array}$ & 1,86 & 1,5 & 2,24 & 2,0 & & 1,95 & & & $1,09-2,24$ \\
\hline
\end{tabular}
with hardened cement paste without SP $[16,17]$.

Table 2. The values of the coefficient $k_{S H, C P}$ in eq. (2) 


\begin{tabular}{|c|c|c|c|c|c|c|c|c|c|c|}
\hline 2 & $\begin{array}{c}1,5- \\
2,04\end{array}$ & $\begin{array}{c}2,33 \\
3,2\end{array}$ & 1,3 & & & & & & & $1,3-3,2$ \\
\hline 3 & 0,84 & & 0,88 & & & & & & & $0,84-0,88$ \\
\hline 4 & & & & 1,05 & 1,17 & 1,42 & 1,24 & & & $1,05-1,42$ \\
\hline 5 & & & & 1,68 & & 0,98 & 1,16 & & & $0,98-1,68$ \\
\hline 6 & & & & & 1,22 & 1,2 & 1,36 & & & $1,2-1,36$ \\
\hline 7 & 0,81 & 1,03 & & & & 1,07 & & 0,97 & 1,09 & $0,81-1,09$ \\
\hline 8 & & 1,0 & & & & & & 1,02 & 1,04 & $1,0-1,04$ \\
\hline 9 & & & & & & & & 1,07 & 1,11 & $1,07-1.11$ \\
\hline 10 & 1,27 & 1,54 & & & & & & & 1,74 & $1,27-1,54$ \\
\hline Range & $0,81-$ & $\begin{array}{c}1,0- \\
2,04\end{array}$ & $\begin{array}{c}0,88- \\
1,5\end{array}$ & $\begin{array}{c}1,05- \\
2,24\end{array}$ & $\begin{array}{c}1,17- \\
2,0\end{array}$ & $\begin{array}{c}0,98- \\
1,42\end{array}$ & $\begin{array}{c}1,16- \\
1,95\end{array}$ & $\begin{array}{c}0,97- \\
1,07\end{array}$ & $\begin{array}{c}1,04 \\
1,74\end{array}$ & \\
\hline
\end{tabular}

Notes: Cement factories: 1-"Proletary"; 2 - "October"; 3-"Oskolcement" 4"Belgorodcement" 5- "Volskcement"; 6 - "Maltsovsky"; 7-"Sebryakovsky"; 8"Verhnebakansky"; 9-"Pervomaysky"

SP: 1- C-3 (SP-1); 2- Melment F 10; 3- Flux-1; 4- Structuro 530; 5- Glenium 30; 6Glenium 51; 7-Glenium ACE 430; 8-Glenium 323 MIX; 9-Glenium 115; 10- Rheobuild $181 \mathrm{~K}$

\section{Results}

Obviously, the use of SP based on polycarboxylate esters has a lesser effect on the shrinkage of cement stone ( $\mathrm{kSH}, \mathrm{CC}$ values are 0.84 to 1.68) compared with $\mathrm{SP}$ on another basis ( $\mathrm{kSH}, \mathrm{CC}$ values are from 1, 09 to 3.2). According to [20], when $25 \%$ from the mass of cement of white ash and metakaolin is added to the concrete, the values of the coefficient $\mathrm{kSH}, \mathrm{SP}$ are from 0.92 to 1.07 . Thus, the "limiting" value of the coefficient $\mathrm{kSH}, \mathrm{SP}$ according to our data can be from $0.84 \cdot 0.92=0.77$ to $1.68 * 1.07=1.8$.

It is well known that the autogenous shrinkage depends on the $\mathrm{W} / \mathrm{C}$ value of cement paste, the volume of hardened cement paste in concrete, the presence of SP and MA. In accordance with EN 1992-1-1, the autogenous shrinkage depends on the class of concrete. According to [14]:

$$
\varepsilon_{S H, C}=b \cdot k_{V} \cdot 0,07 \cdot\left(\frac{W}{C}\right)^{-2} k_{K} \varepsilon_{S H, K, S P}
$$

In Table 3 some data are demonstrated the effect of SP and MA on the value of the autogenous shrinkage [18-24].

Table 3. The values of the coefficient $k_{S H, K, C P}$ in eq. (4)

\begin{tabular}{|c|c|c|c|c|c|c|}
\hline \multirow{2}{*}{ SP and MA } & \multicolumn{5}{|c|}{ Cement factories } & \multirow{2}{*}{ Range } \\
\cline { 2 - 6 } & 1 & 2 & 3 & 4 & 5 & \\
\hline $1-10 \%$ & 1,73 & & & & & 1,73 \\
\hline $2-10 \%$ & 1,81 & & & & & 1,81 \\
\hline $3-10+10 \%$ & 2,6 & & & & & 2,6 \\
\hline 4 & 2,83 & & & & & 2,83 \\
\hline
\end{tabular}




\begin{tabular}{|c|c|c|c|c|c|c|}
\hline 5 & 2,05 & & & & & 2,05 \\
\hline 6 & 1,1 & & & & & 1,1 \\
\hline 7 & 1,78 & 0,57 & 1,89 & & & $0,57-1,89$ \\
\hline 8 & & 0,59 & 0,98 & & & $0,59-0,98$ \\
\hline 9 & & 0,71 & 0,85 & & & $0,71-0,85$ \\
\hline 10 & 2,14 & 0,93 & 1,18 & & & $0,93-1,18$ \\
\hline 11 & & 0,87 & 0,64 & & & $0,64-0,87$ \\
\hline 12 & & $0,32-0,38^{* *}$ & & $0,77-0,95$ & & $0,32-0,95$ \\
\hline 13 & & $1,13-2,8^{* *}$ & & $1,05-1,64$ & 0,82 & $0,82-2,8$ \\
\hline 14 & & $1,4-1,43^{* *}$ & & $1,15-1,76$ & & $1.15-1,76$ \\
\hline Range & $1,1-$ & $0,32-2,8$ & $0,64-$ & $0,77-1,76$ & 0,82 & \\
\hline
\end{tabular}

Notes: Cement factories: 1 - "Proletary"; 2 - "Volskcement"; 3 - "Maltsovsky"; 4 "Pervomaysky"; 5 - "October"

SP and MA: 1 - white ash; 2 - metakaoline; 3 - white ash + metakaoline; 4 - Glenium 51; 5 - Melflux5581; 6 - Melflux2651; 7 - Melflux2641; 8 - Melflux2651; 9 - Melflux5581; 10 - Glenium 30; 11 - Glenium 51; 12 - Glenium ACE 430; 13 - Glenium 323 MIX; 14 Glenium 115; ** - depending on the dosage of SP

It is obvious that when SP and MA is used the effect on the value of the autogenous shrinkage may be different, because SP and MA may change the kinetics of the formation of the crystalline structure in the early period of hardening [25].

\section{Discussion}

To assess the effect of SP, MA, cement properties and mix proportion of concrete on the shrinkage of concrete, the model [26] for determination of the modulus of elasticity and the coefficient of creep of concrete can be used:

$$
E_{0, C}=\frac{2}{\frac{1}{E_{0, C S} V_{C S}+E_{0, C A} V_{C A}+E_{F A} V_{F A}+E_{0, T Z} V_{T Z}}+\frac{V_{C}}{E_{0, C}}+\frac{V_{C A}}{E_{0, C A}}+\frac{V_{F A}}{E_{F A}}+\frac{V_{T Z}}{E_{0, T Z}}}
$$

If to imagine that the shrinkage is equel a deformation caused by some "single" stress $\sigma$ $(\mathrm{sh}, \mathrm{C})=1$ :

$$
\sigma_{s h, C}=E_{0, C} \cdot \varepsilon_{s h, C} \quad 1=E_{0, C} \cdot \varepsilon_{s h, C}
$$

or after a series of transformations

$$
\varepsilon_{s h, C}=\frac{1}{E_{0, C}} \quad E_{0, C}=\frac{1}{\varepsilon_{s h, c}}
$$

the next equation can be obtained 


$$
\varepsilon_{S h, c}=\frac{0,5}{\frac{V_{C S}}{\varepsilon_{S h, C S}}+\frac{V_{C A}}{\varepsilon_{S h, C A}}+\frac{V_{F A}}{\varepsilon_{S h, F A}}+\frac{V_{T Z}}{\varepsilon_{S h, T Z}}}+\frac{V_{C S^{*}} \varepsilon_{S h, C S}+V_{C A^{*}} \varepsilon_{S h, C A}+V_{F A^{*}} \varepsilon_{S h, F A}+V_{T Z} \varepsilon_{S h, T Z}}{2}
$$

in eq. (8): $V_{C A}, V_{T Z,}, V_{C S}, V_{F A}$ - the volume of coarse aggregate, transition zone, hardened cement paste, fine aggregate.

In the table 4 the results of calculating the drying shrinkage using eq. (8) are presented.

Table 4. The calculating values of the drying shrinkage in accordance with eq. (8)

\begin{tabular}{|c|c|c|c|c|c|c|c|}
\hline \multirow{3}{*}{$\begin{array}{l}\text { Type of } \\
\text { concrete }\end{array}$} & \multicolumn{7}{|c|}{ Concrete structure and properties } \\
\hline & \multirow[t]{2}{*}{$V_{C A}$} & \multirow[t]{2}{*}{$V_{C S}$} & \multirow[t]{2}{*}{$\mathrm{W} / \mathrm{C}$} & \multirow[t]{2}{*}{$\varepsilon_{\mathrm{sh}, \mathrm{CS}}$} & \multirow[t]{2}{*}{$\varepsilon_{\mathrm{sh}, \mathrm{b}}, \% 0(\%)$} & \multicolumn{2}{|c|}{$\varepsilon_{\mathrm{cd}, 0}$ table 3.2 EN 1992-1-1 } \\
\hline & & & & & & $\mathrm{C} 40 / 50$ & $\mathrm{C} 60 / 75$ \\
\hline \multirow[t]{2}{*}{$\mathrm{OC}$} & 0,43 & 0,265 & 0,5 & 3 & $0,45(100)$ & $0,46 / 0,38$ & \\
\hline & 0,43 & 0,31 & 0,35 & 2,25 & $0,4(100)$ & & $0,36 / 0,3$ \\
\hline \multirow{2}{*}{$\mathrm{SCC}^{1}$} & 0,34 & 0,265 & 0,5 & 3 & $0,44(98)$ & & \\
\hline & 0,34 & 0,31 & 0,35 & 2,25 & $0,4(100)$ & & \\
\hline \multirow{2}{*}{$\mathrm{SCC}^{2}$} & 0,34 & 0,265 & 0,5 & 4,5 & $0,76(169)$ & & \\
\hline & 0,34 & 0,31 & 0,35 & 4,05 & $0,68(170)$ & & \\
\hline \multirow[t]{2}{*}{$\mathrm{SCC}^{3}$} & 0,34 & 0,265 & 0,5 & 2,4 & $0,37(82)$ & & \\
\hline & 0,34 & 0,31 & 0,35 & 1,8 & $0,28(70)$ & & \\
\hline
\end{tabular}

Notes: 1 - SP and MA do not influence on the drying shrinkage of hardened cement paste

2 - SP and MA increase the drying shrinkage of hardened cement paste up to $80 \%$

3 - SP and MA reduce the drying shrinkage of hardened cement paste up to $20 \%$

The analysis of the data in Table 4 shows that the main effect on the drying shrinkage of SCC is possibly depend on influence of SP and MA on the drying shrinkage of the hardened cement paste. The shrinkage value of the concrete is well described by equation

$$
\varepsilon_{s h, c}=V_{c S}^{1,45} \cdot \varepsilon_{s h, C S}
$$

Concretes made with SP and MA may have the potential lower shrinkage. The shrinkage value can be lowered from $30 \%$ till $70 \%$. It depends on the influence of SP or MA on the drying shrinkage of hardened cement paste which is the determining factor in the quantitative value of the drying shrinkage of concrete.

In the table 5 the results of calculating the autogenous shrinkage using eq (8) are presented.

Table 5. The calculating values of the autogenous shrinkage in accordance with eq. (8)

\begin{tabular}{|c|c|c|c|c|c|c|c|}
\hline \multirow{2}{*}{$\begin{array}{c}\text { Type of } \\
\text { concrete }\end{array}$} & \multicolumn{7}{|c|}{ Concrete structure and properties } \\
\cline { 2 - 8 } & $V_{C A}$ & $V_{C S}$ & $\mathrm{~W} / \mathrm{C}$ & $\varepsilon_{\text {sh,CS }}$ & $\begin{array}{c}\varepsilon_{\text {sh, b }, \% 0} \\
(\%)\end{array}$ & \multicolumn{2}{|c|}{$\varepsilon_{\mathrm{ca}(\infty)} \mathrm{EN} 1992-1-1$} \\
\hline & & & & & & $\mathrm{C} 40 / 50$ & $\mathrm{C} \mathrm{60/75}$ \\
\hline \multirow{2}{*}{$\mathrm{OC}$} & 0,43 & 0,265 & 0,5 & 0,6 & $\begin{array}{c}0,08 \\
(100)\end{array}$ & 0,075 & \\
\cline { 2 - 8 } & 0,43 & 0,31 & 0,35 & 1,2 & $\begin{array}{c}0,185 \\
(100)\end{array}$ & & 0,125 \\
\hline $\mathrm{SCC}^{1}$ & 0,34 & 0,265 & 0,5 & 0,6 & $\begin{array}{c}0,08 \\
(100)\end{array}$ & & \\
\hline
\end{tabular}




\begin{tabular}{|c|c|c|c|c|c|l|l|}
\hline & 0,34 & 0,31 & 0,35 & 1,2 & $\begin{array}{c}0,185 \\
(100)\end{array}$ & & \\
\hline \multirow{3}{*}{$\mathrm{SCC}^{2}$} & 0,34 & 0,265 & 0,5 & 1,68 & $\begin{array}{c}0,22 \\
(275)\end{array}$ & & \\
\cline { 2 - 8 } & 0,34 & 0,31 & 0,35 & 3,36 & $\begin{array}{c}0,52 \\
(280)\end{array}$ & & \\
\hline $\mathrm{SCC}^{3}$ & 0,34 & 0,265 & 0,5 & 0,2 & $\begin{array}{c}0,025 \\
(30)\end{array}$ & & \\
\hline & 0,34 & 0,31 & 0,35 & 0,36 & $\begin{array}{c}0,048 \\
(26)\end{array}$ & & \\
\hline
\end{tabular}

Notes: 1 - SP and MA do not influence on the autogenous shrinkage of hardened cement paste

2 - SP and MA increase the autogenous shrinkage of hardened cement paste up to $180 \%$

3 - SP and MA reduce the autogenous shrinkage of hardened cement paste up to $70 \%$

Analysis of the data in Table 4 shows that the main effect on the autogenous shrinkage of SCC exerts a possible influence of SP and MA on the autogenous shrinkage of the hardened cement paste. The autogenous shrinkage value of the concrete is well described by equation

$$
\varepsilon_{c a(\infty), c}=V_{c S}^{1,6} \cdot \varepsilon_{c a(\infty), C S}
$$

\section{Conclusion}

Concretes containing SP and MA can potentially have the autogenous shrinkage reduced to $75 \%$, or increased to $180 \%$. The value of the autogenous shrinkage depends on the effect of SP and MA on the autogenous shrinkage of hardened cement paste, which is the determining factor in the quantitative value of the autogenous shrinkage of concrete.

\section{References}

1. S.S. Kaprielov, A.V. Sheinfeld, G.S. Kardumyan, New Modified Concretes (Moskow: Printing house "Paradise", 2010)

2. S.S. Kaprielov, A.V. Sheinfeld, G.S. Kardumyan, V.G. Dondukov, Materials of the II All-Rus. Int. Conf. on Concrete and Reinforced Concrete "Concrete and reinforced concrete are the ways of development" 3, 657-671 (2005)

3. G.S. Kardumyan, S.S. Kaprielov, Building materials 8, 12-15 (2005)

4. E. Tazawa, S. Miyazawa, 4 int. Conf. On High strength/High performance concrete, 321-329 (1996)

5. B.S.M. Persson, AEDIFICATIO, 415 - 433 (1998)

6. G. Nayak, K.K. Shetty, S.S.K. Kumara, J.D. Karkera, V. Khandagale, Int. J. of Earth Sciences and Engineering 8 (2), 173-177 (2015)

7. H. K. Alubaidi, Al-Qadisiya Journal For Engineering Sciences 4 (4), 528-536 (2011)

8. A.M.M. Sheinn, C.T. Tam, F.L. Rodrigo, 29th Conf. on Our World in Concrete \& Structures, 485-494 (2004)

9. F. Aslani, Sh. Nejadi, J. of Civil Engineering and Architecture 6 (1), 93-100 (2012)

10. H H. Alghazali, J J. Myers, ACMSM23, 89-94 (2014)

11. K.K. Shetty, G. Nayak, M.D. Shriharsha, A. Siddik, Int. J. of Civil Engineering and Technology 8 (8), 324-333 (2017) 
12. Y.L. Bhirud, K.K. Sangle, Open J. of Civil Engineering 7, 130-140 (2017)

13. W.-J. Long, K.H. Khayat, F. Xing, Open J. of Civil Engineering 5, 116-123 (2011)

14. N.N. Kalinovskaya, D.S. Kotov, E.A. Ivanova, Concrete Technology 11-12, 14 - 17 (2017)

15. G.V. Nesvetaev, Concrete (Rostov: Fenix, 2013)

16. G.V. Nesvetaev, A.N. Davidyuk, Building materials 8, 52-53 (2009)

17. G.V. Nesvetaev, I.V. Korchagin, Scientific review 11-2, $406-407$ (2014)

18. G.V. Nesvetaev, Concrete Technology 5, 50 - 53 (2009)

19. G.V. Nesvetaev, A.N. Davidyuk, Building materials 3, 38-40 (2010)

20. G.V. Nesvetaev, G.S. Kardumyan, T.V. Fan, L.A. Khomich, A.M. Blyagoz, New technologies 4, 125-128 (2012)

21. G.V. Nesvetaev, I.V. Korchagin, Yu.I. Potapova, Scientific review 7, 842-846 (2014)

22. G.V. Nesvetaev, I.V. Korchagin, Naukovedenie 7 (5), 1-12 (2015)

23. S.A. Udodov, M.V. Bychkov, Naukovedenie 4 (17), 1-7 (2013)

24. M.S. Saidumov, M.Sh. Salamanova, T.S.A. Murtazaeva, M.S.M. Hubayev, Innovations and investments 8, 163-166 (2015)

25. G.V. Nesvetaev, Yu.I._Koryanova, MATEC Web of Conferences 129, 1-6 (2017)

26. G.V. Nesvetaev, I.V. Korchagin, Yu.Yu. Lopatina, Solid State Phenomena 265, 109113 (2017) 